\title{
CAFfeine teratogenicity in RATS: MORPhOLOGICAL CHARACTERIZATION AND HYPOTHESIZED MECHANISMS
}

\author{
Ana Cláudia de Souza ${ }^{1,2}$, Jairo Alberto Dussán-Sarria ${ }^{1,2}$, \\ Andressa de Souza ${ }^{2,3}$, Wolnei Caumo ${ }^{1,4}$, Iraci Lucena da Silva Torres ${ }^{1,2,4}$
}

\begin{abstract}
Caffeine consumption during pregnancy has been shown in the scientific literature to be associated with teratogenicity such as low birth weight, fetal malformations, and miscarriage. However, the morphological alterations of the offspring of dams exposed during pregnancy have not been consistently described, and the mechanisms why they occur remain elusive. Thus, we aimed to characterize the offspring malformations induced by moderate and high doses of caffeine during pregnancy. Dams were divided into three groups: control, moderate $(0.3 \mathrm{~g} / \mathrm{L})$, and high dose $(1.0 \mathrm{~g} / \mathrm{L})$ of caffeine, which was provided in the drinking water beginning on gestational day 1 and continuing throughout the entire gestation. At moderate doses, only one of the dams had stillborn pups, although no macroscopic malformations were observed. High doses of caffeine induced significantly more malformations $(P<0.001)$ and early death (before P4). The malformations observed were related to fetal development and cardiovascular alterations, namely bruises, macrocephaly with short limbs, abnormal development (or absence) of head structures and limbs, labial malformations, hydrops fetalis, and poor placental formation. We discussed the proposed mechanisms by which caffeine might induce these phenotypes, which may involve down-regulation of adenosine A1 receptors, and increased mothers' catecholamines. Our findings further confirm the evidence of the teratogenic effects of high doses of caffeine administered during pregnancy. These findings support the recommendation to avoid caffeine exposure during pregnancy.
\end{abstract}

Keywords: Caffeine; offspring; teratogenicity; pregnancy; hydrops; cardiovascular alterations

Different foods contain variable quantities of caffeine, including tea, coffee, soda, energy drinks, chocolate and analgesic formulations ${ }^{1,2}$. When consumed during pregnancy, caffeine might increase the risk for miscarriage ${ }^{3}$, stillbirth ${ }^{4}$, fetal growth restriction ${ }^{5}$, and low birth weight ${ }^{6}$. Thus, regulatory agencies worldwide recommend pregnant women against consuming more than 200-300 mg/day of caffeine (FDA, FSA and WHO), which is equivalent to a "moderate dose" of coffee or two espressos per day. Together, two espressos (around 44-60 mL) contain around $200 \mathrm{mg}$ of caffeine. Nevertheless, consuming more than two espressos per day or its equivalent is not uncommon and neither is consuming foods containing even higher doses of caffeine (i.e. $600 \mathrm{mg}$ of caffeine per day) ${ }^{7}$.

Determining a safety window for caffeine consumption during pregnancy is difficult. Although epidemiological studies have found correlation of caffeine with birth defects only with doses above $600 \mathrm{mg}$ per day ${ }^{7}$, experimental studies in animals have confirmed that lower caffeine doses, around $30 \mathrm{mg} / \mathrm{kg} /$ day by mouth, which is considered moderate ${ }^{8}$, can predispose offspring to seizures ${ }^{9}$, altered locomotive activity ${ }^{10}$, increased emotional reactivity, impulsivity ${ }^{11}$, and impaired cognitive functioning ${ }^{12}$. The oral consumption of caffeine doses higher than $60 \mathrm{mg} / \mathrm{kg} / \mathrm{day}$ might even induce spontaneous abortion ${ }^{13}$, low birth weight ${ }^{6,14}$, intrauterine growth retardation ${ }^{5}$, and induce teratogenicity ${ }^{15}$. Furthermore, the detailed description of the types of malformations induced by caffeine consumption during pregnancy remains elusive.

When facing such ambiguity, it is a challenge to convince the pregnant population to avoid caffeine consumption. Defining whether morphological
Clin Biomed Res. 2016;36(4):179-186

1 Postgraduate Program in Medical Sciences, Universidade Federal do Rio Grande do Sul (UFRGS). Porto Alegre, RS, Brazil.

2 Animal Experimentation Unit, Hospital de Clínicas de Porto Alegre. Porto Alegre, RS, Brazil.

3 Postgraduate Program in Health and Human Development, Centro Universitário La Salle (Unilasalle). Canoas, RS, Brazil.

4 Department of Pharmacology, Instituto de Ciências Básicas da Saúde (ICBS), Universidade Federal do Rio Grande do Sul (UFRGS). Porto Alegre, RS, Brazil.

Corresponding author: Iraci Lucena da Silva Torres iracitorres@gmail.com Pharmacology Department, Instituto de Ciências Básicas da Saúde (ICBS), Universidade Federal do Rio Grande do Sul (UFRGS)

Rua Sarmento Leite, 500, sala 202. 90050-170, Porto Alegre, RS, Brazil. 
malformations might be associated to moderate or to high doses of caffeine and improving the description and understanding of the alterations induced during fetal development, might help sensitize patients and caregivers against consumption of products with caffeine during pregnancy. Thus, we aimed to further characterize the malformations induced by moderate and high caffeine intake during pregnancy, and discuss the possible mechanisms involved.

\section{METHODS}

\section{Animals}

Adult female Wistar rats (weighting approximately $220 \mathrm{~g}$ ), 90 days old were submitted to vaginal lavage to verify the estrous cycle. In their fertile phase, females were housed in the evening with a fertile male. The following morning, males were removed and the vaginal smears were collected. Mating was confirmed by sperm presence in vaginal smears. The day of sperm detection in the vaginal smears was considered as day 0 (G0). All animals were housed individually in cages made of polypropylene material $(49 \times 34 \times 16 \mathrm{~cm})$ of laboratory-grade and were maintained in a standard 12:12 hour light/dark cycle (lights on at 07:00 a.m. and lights off at 07:00 p.m.) in a controlled environment $\left(22 \pm 2^{\circ} \mathrm{C}\right)$. Animals had access to water or caffeinated water, and chow ad libitum. The experiments and procedures were approved by the Institutional Committee for Animal Care and Use (GPPG-Hospital de Clínicas de Porto Alegre protocol N. 110034) and conformed to the Laboratory Guide for the Care and Use of Animals (The National Academies Press, Eighth Edition, 2011). Animal handling and all experiments were performed in accordance with international guidelines for animal welfare and measures were taken to minimize animal pain and discomfort.

\section{Interventions}

The dams were divided into three groups ( $\mathrm{n}=9$ per group) according to the intervention administered, namely (1) Control group, which received only tap water; (2) moderate caffeine consumption, which received $0.3 \mathrm{~g} / \mathrm{L}$ of caffeine (Sigma Chemical Co; St. Louis, MO, USA) dissolved in tap water; and (3) high caffeine consumption, which received $1.0 \mathrm{~g} / \mathrm{L}$ of caffeine dissolved in tap water. Caffeine was provided in the drinking water from the first gestational day, and continued during the entire gestational period (21 days).

\section{Assessments}

Water consumption was measured every other day for each dam, starting on the first gestational day (G1). Photographical registry and description of the litter was performed immediately after birth. However, to avoid mothers' stress and possible rejection of the litter due to human manipulation, pups were only weighed on the second postnatal day.

\section{Statistical Analysis}

Variables were summarized using conventional descriptive statistics. Birth-weight and water consumption were compared between groups using one-way Analysis of Variance (ANOVA). To determine the association of caffeine with the presence of malformations, the Fisher's exact test was used. Statistical significance was set to a $P$ value of 0.05 . The data were analyzed using SPSS version 18.0 (SPSS, Chicago, IL).

\section{RESULTS}

A total of 27 female rats were used in the experiment, and each dam delivered between 5-14 pups.

\section{Dams Water Consumption}

The water intake did not differ significantly between dams (one-way ANOVA, $P>0.05$ ). Controls drank $43.8 \pm 12.67$ (mean $\pm S D$ ) $\mathrm{mL} /$ day, the moderate dose group, $47.4 \pm 9.54 \mathrm{~mL} /$ day (approximately $142.2 \mathrm{mg}$ of caffeine per day), and the high dose group drank $49.0 \pm 10.32 \mathrm{~mL} /$ day (490.0 $\mathrm{mg}$ of caffeine per day).

\section{Control Group ( $n=9$ dams) Offspring Observations}

The dams that received water and standard food conceived normal term litter (21 gestational days) (figure 1). Each dam conceived 10-14 pups.

\section{Moderate Dose of Caffeine ( $0.3 \mathrm{~g} / \mathrm{L})$ ( $n=9$ dams) Offspring}

One of the dams $(14 \%)$ that received water with caffeine at $0.3 \mathrm{~g} / \mathrm{L}$, had only stillborn pups $(\mathrm{n}=8)$, with no visible malformations. The rest of the dams conceived normal offspring, each with 8-12 pups.

\section{High Dose of Caffeine (1 $\mathrm{g} / \mathrm{L}$ ) ( $n=9$ dams) Offspring}

No preterm births were observed, but there were two dams $(23 \%)$ that had only stillborn pups (6-8) without visible malformations. Two of the dams $(23 \%)$ had their whole litter with some degree of malformation: In the litter of the first dam (6 pups), it was observed bruises on the body (figure 2a and figure $2 b$ ), macrocephaly with short limbs (figure $2 c$ and figure d), abnormal development (or absence) of head structures (i.e. mouth, ears, eyes) and limbs (figure 2e), labial malformations (figure 2e) and hydrops fetalis (figure 2f). In the litter of the second dam, although all the products of gestation were at term (8 pups), severe malformations were observed 
(figure 3), including poor placental formation, limbs absence and abnormal development (or absence) of head structures (i.e. mouth, ears, eyes). The litter of a third dam $(11 \%)$ had no evidence of malformations. Nevertheless, the whole third litter was victim of cannibalistic behavior by the mother. Although the other three litters $(43 \%)$ did not have evidence of malformations, $80 \%$ of the offspring spontaneously died between $\mathrm{P} 1$ and $\mathrm{P} 4$. Each dam conceived 6-9 pups and had 21 days of gestation. The final 2 litters

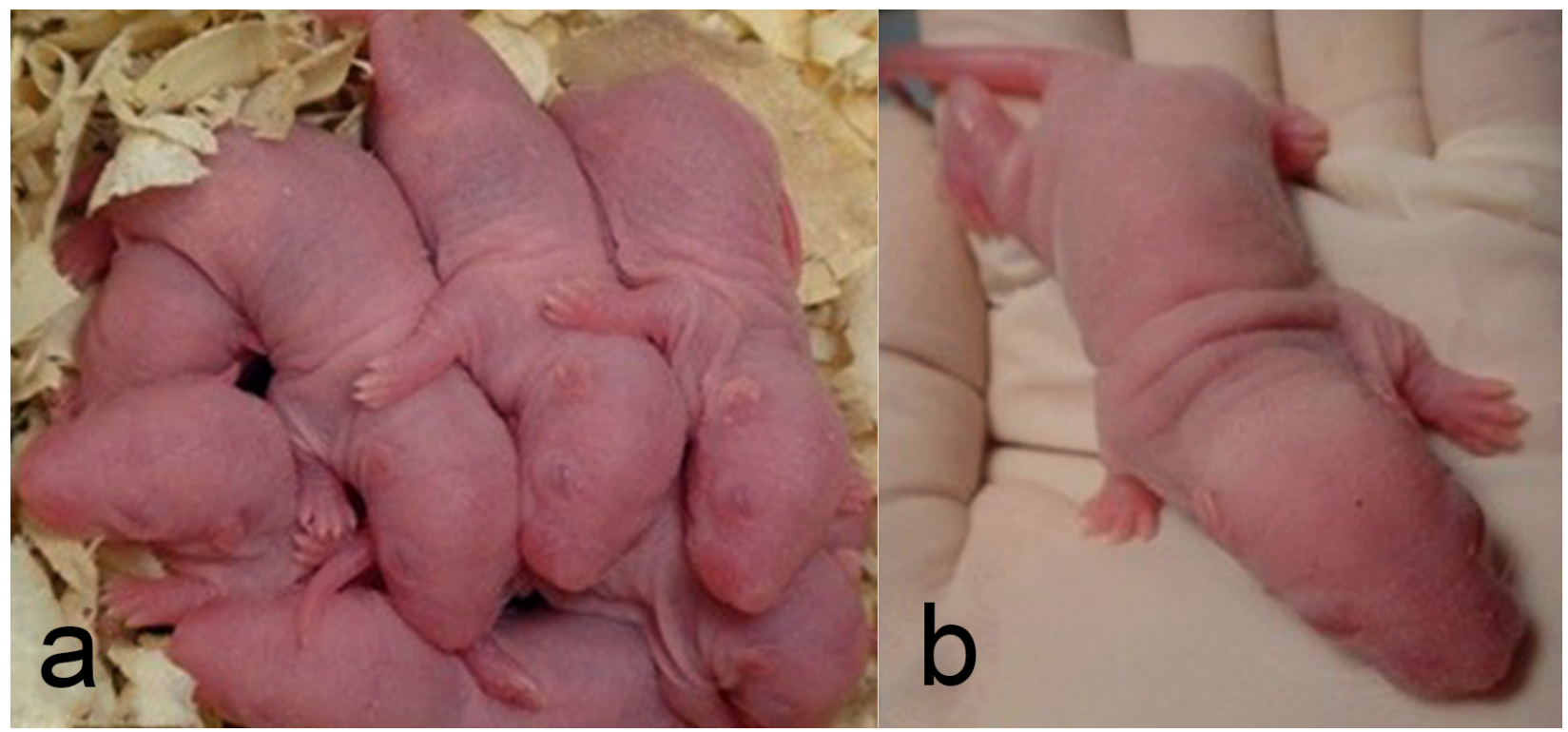

Figure 1: Appearance of a normal litter (control group). Part a presents the appearance of a normal litter at the first postnatal day. Part b presents its appearance at the third postnatal day. Notice the proportion of the head, limbs, and presence of lanugo hair.

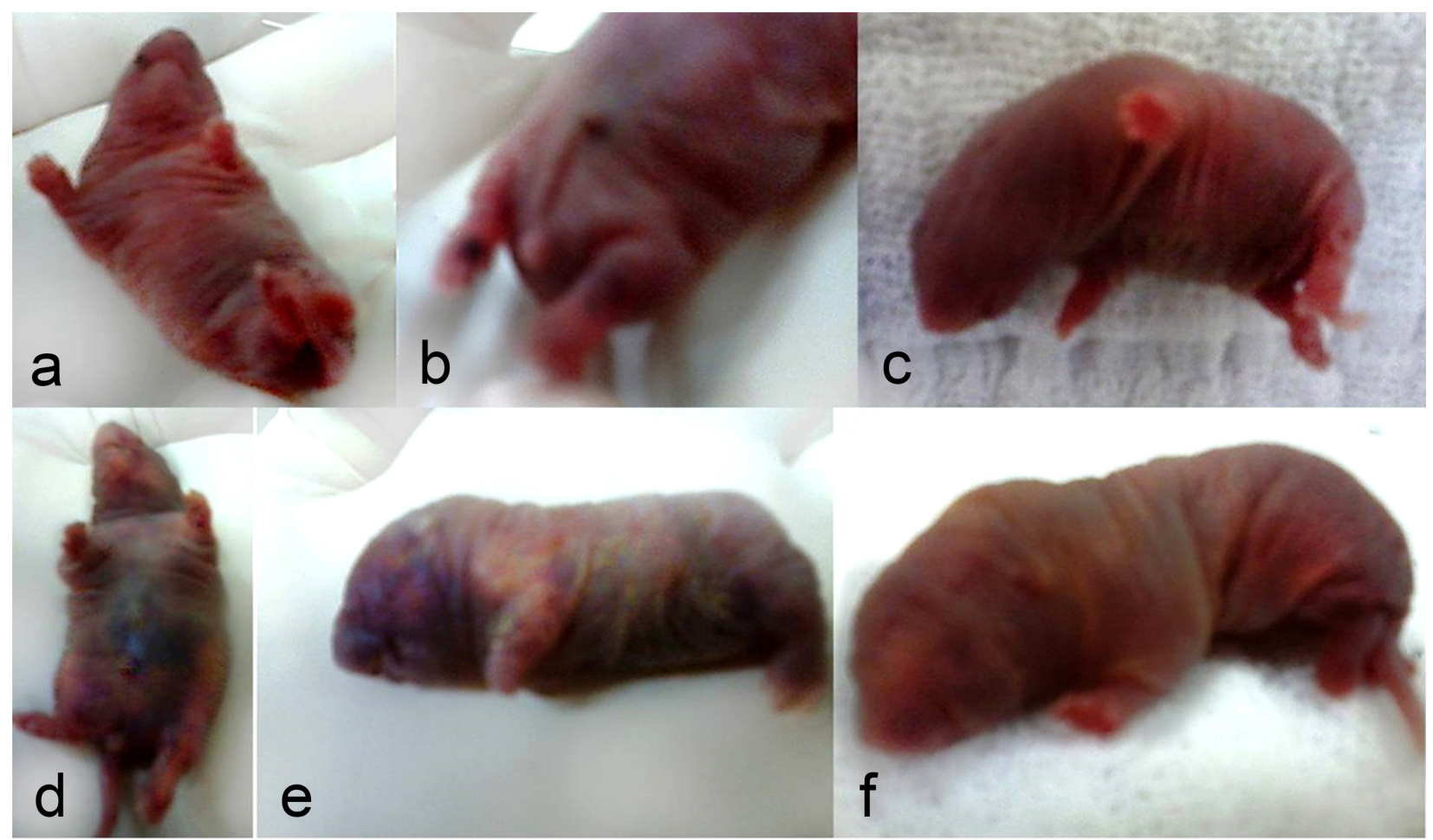

Figure 2: Malformations in the first dam of rats exposed to a sustained high dose of caffeine $(1 \mathrm{~g} / \mathrm{L})$. The picture presents the bruises ( $a$ and b), macrocephaly with short limbs ( $c$ and d), abnormal development (or absence) of head structures (i.e. mouth, ears, eyes) and limbs (e), and hydrops fetalis (f). 
(23\%) that had confirmed pregnancy (through sperm presence in vaginal smears and weigh gain) did not give birth. We inferred that the rats had spontaneous abortions early in the pregnancy, because no evidence of birth neither of cannibalism was observed. There were significantly more malformations in the litter of dams that received a high dose of caffeine during pregnancy, while the presence of malformations in the litters from dams exposed to moderate caffeine doses were not significantly different from controls (Fisher's exact test, $P<0.001$, see table 1).

\section{Birth Weight}

The offspring of the dam exposed to moderate dose of caffeine had significantly lower birth weight. At birth, the control group litter mean weight was
$7.11 \pm 0.49 \mathrm{~g}$, while the moderate dose of caffeine litter weighted $6.64 \pm 0.54 \mathrm{~g}(\mathrm{t}=-2.237, P=0.031)$. None of the rats with malformations were weighted, because malformations occurred in both senses inducing high variability: some of the rats were extremely small at birth (figure $3 \mathrm{~g}$ ) while some malformations were associated to an increase in body size (figure $2 \mathrm{~d}$ ).

\section{DISCUSSION}

Our experiment describes the characteristics of the teratogenicity induced by exposure to high doses of caffeine during pregnancy in rats. Moderate doses of caffeine (142.2 mg per day), did not induce a significant number of malformations, while a high dose (490.0 mg of caffeine per day) induced significant

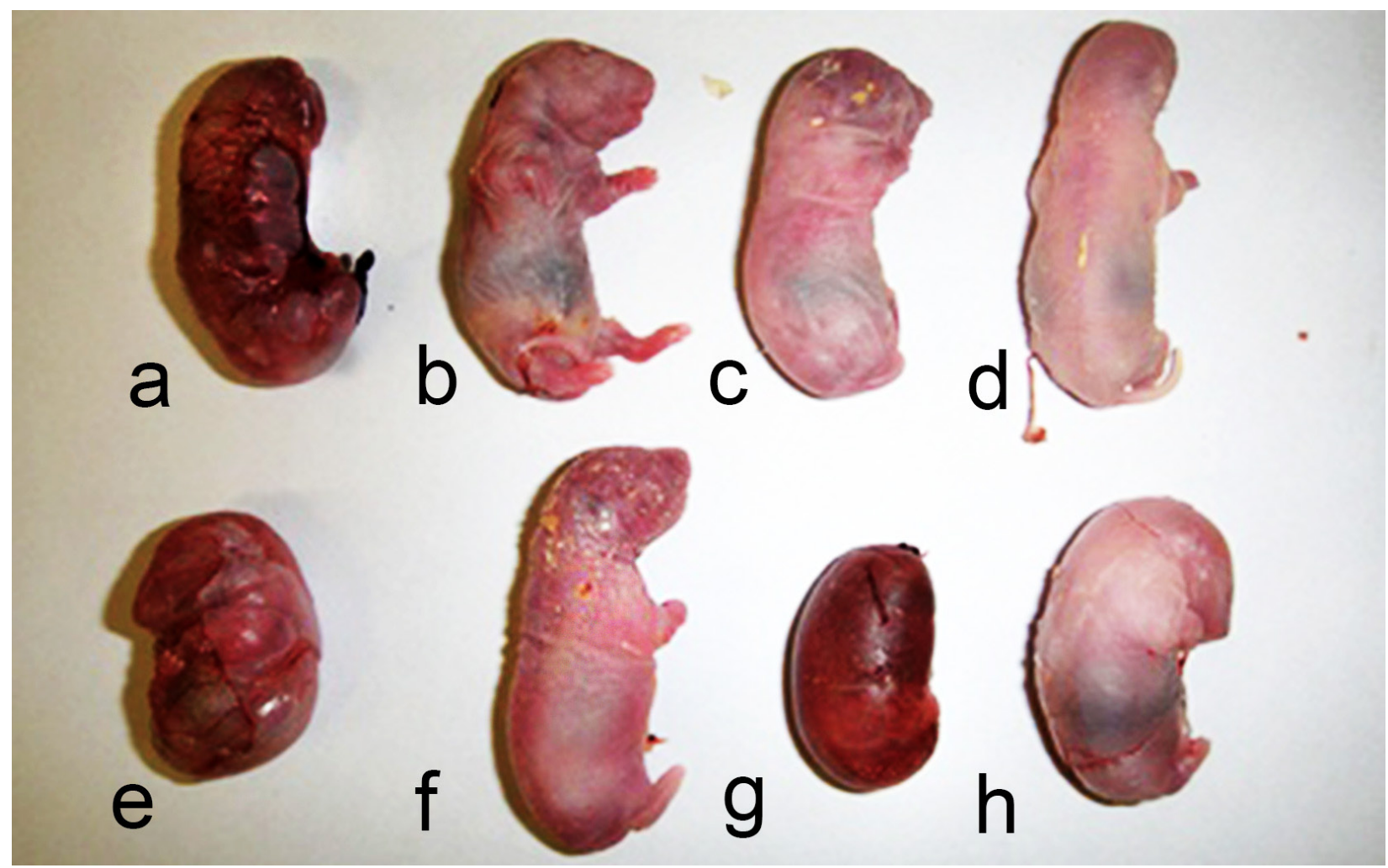

Figure 3: Spectrum of malformations in the offspring of rats exposed to a sustained high dose of caffeine (1 $\mathrm{g} / \mathrm{L})$. The picture presents the spectrum of malformations induced, from absence of structures differentiation, going through short head and limbs.

Table 1: Tabulation of the presence of malformations in the dams according to the intervention. The dams exposed to high doses of caffeine presented litter with significantly more malformations, while litters of those exposed to a moderate dose did not differ from controls.

\begin{tabular}{lccccc}
\hline & & \multicolumn{2}{c}{ Number of dams with malformations } & \multirow{2}{*}{ Total } \\
\cline { 3 - 5 } & & Control & Moderate dose & High dose & \\
\hline \multirow{3}{*}{ Any malformation } & Yes & $0^{\mathrm{a}}$ & $1^{\mathrm{a}}$ & $9^{\mathrm{b}}$ & 10 \\
& No & $9^{\mathrm{a}}$ & $8^{\mathrm{a}}$ & $0^{\mathrm{b}}$ & 17 \\
& Total & 9 & 9 & 9 & 27 \\
\hline
\end{tabular}

Shared letter denotes categories whose column proportions do not differ significantly from each other at the 0.05 level. 
teratogenicity, manifesting as malformations of the cardiovascular and renal system including petechiae, hematomas (sign of capillary fragility), and hydrops fetalis ("swollen appearance"; accumulation of fluids). Our findings are in agreement with other studies evaluating exposure to caffeine during fetal development, which have described malformations of the cardiovascular system ${ }^{16-18}$. Different mechanisms addressing the teratogenic effects of caffeine have been proposed, including down-regulation of adenosine receptors, induction of catecholamine release, phosphodiesterase inhibition, and mutagenic role due to its similarity with purine components.

When chronically administered to pregnant rats, caffeine is capable of down-regulating adenosine A1 receptors, and this decrease can cause changes in the formation of fetal cardiovascular tissues ${ }^{16}$. Adenosine plays a key role in protecting the embryo against intrauterine stress such as hypoxia; particularly through $\mathrm{A} 1$ receptors expressed in the heart ${ }^{19}$, and it has potent effects (in vitro and in vivo) on the cardiovascular system of different species ${ }^{20,21}$. During embryogenesis, adenosine A1 receptors are the dominant regulator of embryonic heart rate. On the other hand, caffeine can alter the embryonic cardiac function, disrupting the cardiac response to hypoxia through blockade of adenosine action on the $\mathrm{A} 1$ receptors $^{18}$. Thus, caffeine-induced down-regulation of adenosine A1 receptors is one of the plausible mechanisms supporting the cardiovascular teratogenicity observed in our study.

Other pathophysiological mechanisms of caffeine might have been related to the observed malformations. Caffeine decreases the blood supply in the placenta ${ }^{22}$, which promotes reduction of fetal osmotic plasma pressure and increments in capillary permeability due to the abnormal transportation of water in intracellular and extravascular tissues ${ }^{23}$. Supporting this hypothesis, it has been demonstrated that caffeine teratogenic effects might occur by virtue of catecholamine release from maternal adrenal glands or embryonic tissues ${ }^{24-26}$. Mineralocorticoids favor liquid retention through sodium uptake, loss of potassium, and vasoconstriction of placental arterioles, which prejudices nutrients exchange and favors maternal and fetal hypertension ${ }^{27}$. In turn, the insufficient blood flow to the placenta after exposure to caffeine leads to fetal hypoxia, followed by intrauterine growth retardation or uterine vasoconstriction maintained by catecholamines ${ }^{28}$. Tofovic and colleagues ${ }^{29}$ demonstrated that caffeine augments renin release sympathetically mediating increased sympathetic tone, supporting the fact that caffeine increases renin secretion under basal conditions and in response to various stimuli by blocking intrarenal adenosine receptors. A recent study using $20 \mathrm{mg} / \mathrm{kg}$ of caffeine subcutaneously in mice (which corresponds to two cups of coffee in humans), revealed that chronic administration of caffeine to pregnant dams led to persistent activation of local renin-angiotensin system in the kidney and heart of the offspring, which in turn, led to high blood pressure and adverse cardiac remodeling ${ }^{30}$. Taken together, the observations of the effects of caffeine on the cardiovascular and renal systems provide a sound explanation of the fluid balance alteration that can lead to the macroscopic malformations presented in our report (i.e. hydrops fetalis, bruises, petechiae or hematomas). The increase of catecholamines in the mother can also be related to miscarriage, stillborn offspring, and changes in mother's and offspring's behavior and motor development ${ }^{31}$. In addition, we observed that one litter had an incomplete fetal development (figure 3). This might also be related to the elevation in maternal glucocorticoids, and to the metabonome alterations that prenatal exposure to caffeine can induce, as relevant discriminatory metabolites might be involved in the metabolic programming of caffeine-induced intrauterine growth retardation ${ }^{5}$.

At high concentrations, caffeine may also have a direct effect on $Y$-aminobutyric acid type $A$ $\left(G_{A B A}\right)^{32,33}$, which could have affected rat behavior. Such neuronal and behavioral changes could explain the cannibalistic behavior observed in some of the dams. Although these dams had an apparently normal litter as assessed on the first postnatal day, by the second day the pups were not found. As our assessments occurred in the morning and in the evening, we can infer that cannibalistic behavior occurred at night, according to the species nocturnal habit. When animals of this species face litters with some degree of deformity or when under stress, the mother presents cannibalistic behavior, even at term ${ }^{34}$. The characteristics of our experiment do not allow us to determine whether cannibalism occurred due to the probable dam behavioral alterations induced by caffeine or due to malformations of the litter.

High doses of caffeine also induced other significant malformations in the limbs and head. Other authors have described caffeine-induced malformations of the limbs and digits (including ectrodactyly), craniofacial malformations (labial and palatal clefts $)^{35,36}$, and delays in ossification of limbs, jaw and sternum ${ }^{37,38}$. In our study, we observed few labial malformations in comparison to literature reports. Such difference might have occurred due to variations in the experimental models employed, as other authors have used different routes of caffeine administration (e.g. intraperitoneal, gavage ${ }^{37}$ ), and 
have combined it with other drugs (e.g. nicotine ${ }^{39}$ ). Overall, craniofacial and limb malformations induced by caffeine have been attributed to a reduction in the number of branchial bars and somites, as well as an impairment in the formation of the forelimb, which occurs on the early morphogenesis of these regions ${ }^{35}$. Even moderate doses of caffeine are capable of inhibiting the phosphodiesterase enzyme that degrades cyclic adenosine monophosphate (cAMP), increasing the CAMP levels which may interfere on growth and development in fetal cells ${ }^{40,41}$.

The mutagenic potential of caffeine can also be related to its chemical similarity to purine components. Caffeine decreases the activity of deoxyribonucleic acid polymerase and the replication of deoxyribonucleic acid. It also increases the cyclic adenosine monophosphate, and cyclic guanosine monophosphate ${ }^{15,42}$. Thus, the incorporation of caffeine into the genetic material alters the instructions of cellular replication ${ }^{43}$, decreasing the mitosis $\mathrm{G} 2$ phase, and consequently the time to repair the chromosomal damage, ultimately increasing the percentage of dead cells ${ }^{44}$.

Applying this animal data to humans should be done with caution, as it deserves relevant considerations. The principal caffeine metabolism occurs via the cytochrome P450, enzyme 1A2 gene (CYP1A2), which is absent in the human placenta and fetus ${ }^{45,46}$. Therefore, the caffeine half-life in humans is increased in fetus and neonates, who cannot metabolize it until approximately 3 months of age ${ }^{47}$. During the first trimester, the half-life is greatly increased 5-6 h, whereas it increases up to 8-9 h between 12 and 20 weeks gestation. Regarding the teratogenicity in humans, the organogenesis period is recognized as the most important, which limits the extrapolation from findings in rats because in this species the post-organogenesis period occurs in the third quarter after birth ${ }^{48}$. Furthermore, rats' neural growth occurs in postnatal life, having that the first 7-10 postnatal days of a rat represent the third trimester of human pregnancy. Also, epidemiological studies indicate that human malformations are only positively associated with high caffeine consumption (600 mg) daily ${ }^{5}$, which is challenging to compare to doses in rats because of their metabolic differences ${ }^{49}$.

Our findings extend the evidence of the teratogenic effects due to high-dose caffeine consumption during pregnancy. Our description of the malformations induced by caffeine support their possible association with changes in the cardiovascular and renal physiology in both the mother and the fetus. These findings support the recommendation to avoid exposure of caffeine during pregnancy. The exact mechanism by which these teratogenic effects may occur has not been fully elucidated. Thus, further research addressing the integration of the mechanisms discussed, their effect on the cardiovascular and renal physiology, and their dosage translation to humans should be performed.

\section{Conflicts of interest}

The authors declare no conflicts of interest.

\section{REFERENCES}

1. Petersen KU. Koffein in Schmerzmitteln Mär oder Medizin? MMW Fortschr Med. 2013;155(S7 Suppl 4):109-14. http://dx.doi. org/10.1007/s15006-013-2541-1.

2. Heckman MA, Weil J, Mejia EG. Caffeine (1, 3, 7-trimethylxanthine) in foods: a comprehensive review on consumption, functionality, safety, and regulatory matters. J Food Sci. 2010;75(3):R77-87. http://dx.doi.org/10.1111/j.17503841.2010.01561.x.

3. Greenwood DC, Thatcher NJ, Ye J, Garrard L, Keogh G, King LG, et al. Caffeine intake during pregnancy and adverse birth outcomes: a systematic review and dose-response meta-analysis. Eur J Epidemiol. 2014;29(10):725-34. http://dx.doi. org/10.1007/s10654-014-9944-x.
4. Wisborg K, Barklin A, Hedegaard M, Henriksen TB. Psychological stress during pregnancy and stillbirth: prospective study. BJOG. 2008;115(7):882-5. http://dx.doi.org/10.1111/j.14710528.2008.01734.x.

5. Kou H, Liu Y, Liang G, Huang J, Hu J, Yan YE, et al. Maternal glucocorticoid elevation and associated blood metabonome changes might be involved in metabolic programming of intrauterine growth retardation in rats exposed to caffeine prenatally. Toxicol Appl Pharmacol. 2014;275(2):7987. http://dx.doi.org/10.1016/j. taap.2014.01.007.

6. Dobson NR, Patel RM, Smith PB, Kuehn DR, Clark J, Vyas-Read $\mathrm{S}$, et al. Trends in caffeine use and association between clinical outcomes and timing of therapy in very low birth weight infants. $J$ Pediatr. 2014;164(5):992-8. http://dx.doi. org/10.1016/j.jpeds.2013.12.025.

7. Bracken MB, Triche EW, Belanger K, Hellenbrand K, Leaderer BP. Association of maternal caffeine consumption with decrements in fetal growth. Am J Epidemiol. 2003;157(5):456-66. http://dx.doi. org/10.1093/aje/kwf220.

8. Folwarczna J, Pytlik M, Zych M, Cegieła U, Kaczmarczyk-Sedlak I, Nowińska B, et al. Favorable effect of moderate dose caffeine on the skeletal system in ovariectomized rats. Mol Nutr Food Res. 2013;57:1772-84.

9. Tchekalarova JD, Kubová H, Mareš $P$ Different effects of postnatal caffeine treatment on two pentylenetetrazoleinduced seizure models persist into adulthood. Pharmacol Rep. 
2013;65(4):847-53. http://dx.doi. org/10.1016/S1734-1140(13)71065-X.

10. Nakamoto T, Roy G, Gottschalk SB, Yazdani M, Rossowska M. Lasting effects of early chronic caffeine feeding on rats' behavior and brain in later life. Physiol Behav. 1991;49(4):721-7. http://dx.doi. org/10.1016/0031-9384(91)90309-C.

11. Anderson NL, Hughes RN. Increased emotional reactivity in rats following exposure to caffeine during adolescence. Neurotoxicol Teratol. 2008;30(3):195-201. http://dx.doi. org/10.1016/j.ntt.2008.02.002.

12. Soellner DE, Grandys T, Nuñez JL. Chronic prenatal caffeine exposure impairs novel object recognition and radial arm maze behaviors in adult rats. Behav Brain Res. 2009;205(1):191-9. http://dx.doi. org/10.1016/j.bbr.2009.08.012.

13. Howards PP, Hertz-Picciotto I, Bech BH, Nohr EA, Andersen AM, Poole $C$, et al. Spontaneous abortion and a diet drug containing caffeine and ephedrine: a study within the Danish national birth cohort. PLoS One. 2012;7(11):e50372. http://dx.doi. org/10.1371/journal.pone.0050372.

14. Bech BH, Obel C, Henriksen TB, Olsen $\mathrm{J}$. Effect of reducing caffeine intake on birth weight and length of gestation: randomised controlled trial. BMJ. 2007;334(7590):409. http:// dx.doi.org/10.1136/bmj.39062.520648. BE.

15. Christian MS, Brent RL. Teratogen update: evaluation of the reproductive and developmental risks of caffeine. Teratology. 2001;64(1):51-78. http:// dx.doi.org/10.1002/tera.1047.

16. Iglesias I, León D, Ruiz MA, Albasanz JL, Martín M. Chronic intake of caffeine during gestation down regulates metabotropic glutamate receptors in maternal and fetal rat heart. Amino Acids. 2006;30(3):25766. http://dx.doi.org/10.1007/s00726005-0293-7.

17. Momoi N, Tinney JP, Liu LJ, Elshershari $\mathrm{H}$, Hoffmann PJ, Ralphe JC, et al. Modest maternal caffeine exposure affects developing embryonic cardiovascular function and growth. Am J Physiol Heart Circ Physiol. 2008;294(5):H224856. http://dx.doi.org/10.1152/ ajpheart.91469.2007.

18. Buscariollo DL, Breuer GA, Wendler CC, Rivkees SA. Caffeine acts via A1 adenosine receptors to disrupt embryonic cardiac function. PLoS One. 2011;6(12):e28296. http://dx.doi. org/10.1371/journal.pone.0028296.

19. Rivkees SA, Wendler CC. Regulation of cardiovascular development by adenosine and adenosine-mediated embryo protection. Arterioscler Thromb Vasc Biol. 2012;32(4):8515. http://dx.doi.org/10.1161/ ATVBAHA.111.226811.

20. Xu Z, Park SS, Mueller RA, Bagnell RC, Patterson C, Boysen PG. Adenosine produces nitric oxide and prevents mitochondrial oxidant damage in rat cardiomyocytes. Cardiovasc Res. 2005;65(4):80312. http://dx.doi.org/10.1016/j. cardiores.2004.12.004.

21. León D, Albasanz JL, Ruíz MA, Martín M. Chronic caffeine or theophylline intake during pregnancy inhibits $\mathrm{A} 1$ receptor function in the rat brain. Neuroscience. 2005;131(2):4819. http://dx.doi.org/10.1016/j. neuroscience.2004.11.028.

22. Kirkinen $P$, Jouppila $P$, Koivula A, Vuori J, Puukka M. The effect of caffeine on placental and fetal blood flow in human pregnancy. $A m \mathrm{~J}$ Obstet Gynecol. 1983;147(8):93942. http://dx.doi.org/10.1016/00029378(83)90250-8.

23. Bellini C, Hennekam RC, Fulcheri E, Rutigliani M, Morcaldi G, Boccardo $F$, et al. Etiology of nonimmune hydrops fetalis: a systematic review. Am J Med Genet. 2009;149A(5):84451. http://dx.doi.org/10.1002/ ajmg.a.32655.

24. Fujii T, Nishimura H. Proceedings: Prevention of embryopathic effects of caffeine in mice by pretreatment with propranolol. Jpn J Pharmacol. 1974;24:44.

25. York RG, Randall JL, Scott WJ JR. Teratogenicity of paraxanthine (1,7-dimethylxanthine) in C57BL/6 J mice. Teratology. 1986;34(3):27982. http://dx.doi.org/10.1002/ tera. 1420340307.

26. Moriguchi M, Scott WJ JR. Prevention of caffeine-induced limb malformations by maternal adrenalectomy. Teratology. 1986;33(3):319-22. http:// dx.doi.org/10.1002/tera.1420330310.

27. Docherty CC, Kalmar-Nagy J, Engelen M, Koenen SV, Nijland M, Kuc $R E$, et al. Effect of in vivo fetal infusion of dexamethasone at $0.75 \mathrm{GA}$ on fetal ovine resistance artery responses to
ET-1. Am J Physiol Regul Integr Comp Physiol. 2001;281(1):R261-8.

28. Liu YA, Ostlund E, Fried G. Endothelin-induced contractions in human placental blood vessels are enhanced in intrauterine growth retardation, and modulated by agents that regulate levels of intracellular calcium. Acta Physiol Scand. 1995;155(4):405-14. http:// dx.doi.org/10.1111/j.1748-1716.1995. tb09990.x.

29. Tofovic SP, Branch KR, Oliver RD, Magee WD, Jackson EK. Caffeine potentiates vasodilator induced renin release. J Pharmacol Exp Ther. 1991;256:850-60.

30. Serapiao-Moraes DF, Souza-Mello $\mathrm{V}$, Aguila MB, Mandarim-de-Lacerda CA, Faria TS. Maternal caffeine administration leads to adverse effects on adult mice offspring. Eur J Nutr. 2013;52(8):1891-900. http://dx.doi. org/10.1007/s00394-012-0490-6.

31. Souza AC, Souza A, Medeiros LF, De Oliveira C, Scarabelot VL, Da Silva RS, et al. Maternal caffeine exposure alters neuromotor development and hippocampus acetylcholinesterase activity in rat offspring. Brain Res. 2015;1595:10-8. http://dx.doi. org/10.1016/j.brainres.2014.10.039.

32. Silva CG, Métin C, Fazeli W, Machado NJ, Darmopil S, Launay PS, et al. Adenosine receptor antagonists including caffeine alter fetal brain development in mice. Sci Transl Med. 2013;5:197ra104.

33. Ribeiro JA, Sebastião AM. Caffeine and adenosine. J Alzheimers Dis. 2010;20(Suppl 1):S3-15.

34. Schardein JL, Petrere JA, Hentz DL, Camp RD, Kurtz SM. Cannibalistic traits observed in rats treated with a teratogen. Lab Anim. 1978;12(2):81-3. http://dx.doi.org/10.1258/0023677787 80953080.

35. Ross CP, Persaud V. Craniofacial and limb development in early rat embryos following in utero exposure to ethanol and caffeine. Anat Anz. 1990;170:914.

36. Collier SA, Browne ML, Rasmussen SA, Honein MA. Maternal caffeine intake during pregnancy and orofacial clefts. Birth Defects Res A Clin Mol Teratol. 2009;85(10):842-9. http:// dx.doi.org/10.1002/bdra.20600.

37. Clark RL, Eschbach K, Cusick WA, Heyse JF. Interactions between 
caffeine and adenosine agonists in producing embryo resorptions and malformations in mice. Toxicol Appl Pharmacol. 1987;91(3):37185. http://dx.doi.org/10.1016/0041008X(87)90059-7.

38. Nehlig A, Debry G. Potential teratogenic and neurodevelopmental consequences of coffee and caffeine exposure: a review on human and animal data. Neurotoxicol Teratol. 1994;16(6):531-43. http://dx.doi. org/10.1016/0892-0362(94)90032-9.

39. Leblebicioglu-Bekcioglu B, Paulson RB, Paulson JO, Sucheston ME, Shanfeld J, Bradway SD. Effects of caffeine and nicotine administration on growth and ossification of the ICR mouse fetus. J Craniofac Genet Dev Biol. 1995;15:146-56.

40. Snyder SH, Sklar P. Behavioral and molecular actions of caffeine: focus on adenosine. $J$ Psychiatr Res. 1984;18(2):91-106. http://dx.doi. org/10.1016/0022-3956(84)90001-3.

41. Fredholm BB, Bättig $K$, Holmén J, Nehlig A, Zvartau EE. Actions of caffeine in the brain with special reference to factors that contribute to its widespread use. Pharmacol Rev. 1999;51:83-133.

42. Leonard TK, Watson RR, Mohs ME. The effects of caffeine on various body systems: a review. J Am Diet Assoc. 1987;87:1048-53.

43. Dlugosz L, Belanger K, Hellenbrand K, Holford TR, Leaderer B, Bracken MB. Maternal caffeine consumption and spontaneous abortion: a prospective cohort study. Epidemiology. 1996;7(3):250-5. http://dx.doi. org/10.1097/00001648-19960500000006 .

44. González-Fernández A, Hernández $P$, López-Sáez JF. Effect of caffeine and adenosine on $\mathrm{G} 2$ repair: mitotic delay and chromosome damage. Mutat Res. 1985;149(2):275-81. http://dx.doi. org/10.1016/0027-5107(85)90034-X.

45. Oesterheld JR. A review of developmental aspects of cytochrome P450. J Child Adolesc Psychopharmacol. 1998;8(3):16174. http://dx.doi.org/10.1089/ cap.1998.8.161.

46. Derkenne S, Curran CP, Shertzer HG, Dalton TP, Dragin N, Nebert DW. Theophylline pharmacokinetics: comparison of Cyp1a1(-/-) and Cyp1a2(-/-) knockout mice, humanized hCYP1A1_1A2 knock-in mice lacking either the mouse Cyp1a1 or Cyp1a2 gene, and Cyp1(+/+) wild-type mice. Pharmacogenet Genomics. 2005;15(7):503-11. http://dx.doi.org/10.1097/01. fpc.0000167326.00411.50.

47. Brent RL, Christian MS, Diener RM. Evaluation of the reproductive and developmental risks of caffeine. Birth Defects Res B Dev Reprod Toxicol. 2011;92(2):152-87. http://dx.doi. org/10.1002/bdrb.20288.

48. Michalek H, Pintor A, Fortuna S, Bisso GM. Brain choline acetyltransferase and muscarinic receptor sites, brain and liver cholinesterases in precocial Acomys cahirinus and altricial rat during post-natal development. Pol $\mathrm{J}$ Pharmacol Pharm. 1988;40:543-51.

49. Nikoui V, Ostadhadi S, Takzare N, Nabavi SM, Giorgi M, Bakhtiarian A. The role of clomipramine in potentiating the teratogenic effects of caffeine in pregnant rats: a histopathological study. ScientificWorldJournal. 2013;2013:382434.

Received: Sept 27, 2016 Accepted Nov 24, 2016: 